\title{
THE THEORY OF FINAL UTILITY
}

IN ITS RELATION TO MONEY AND

\section{THE STANDARD OF DEFERRED PAYMENTS.}

In the AnNaIs for November, I892, appeared a paper on "The Standard of Deferred Payments" by Professor Edward A. Ross, of Cornell University, discussing the subject principally from the standpoint of value. The detection of some errors in his discussion suggested to the present writer the need of a special study of the relation of the theory of final utility to money in general and the standard of deferred payments in particular. $\mathrm{He}$ will first present the results of such a study and then briefly criticise Professor Ross' article in the light of those results.

Although the orthodox conception of value regarded an economic good as embodying a greater or a smaller quantity of value, which quantity was thought to be determined by cost of production, yet the central idea was that of a relation of commodity to commodity. True, the relation necessarily existed between certain quantities-costs of production-but the relation was the principal thing. The expression of this relation was found in market values, in exchange ratios. As a general rise or fall of exchange ratios is obviously impossible, it was declared that there could be no such thing as a general rise or fall of values.

It is quite clear that the classical economists were untrue to their own conception of value as being in the first place quantity and in the second place relations of quantity. Recent writers ascribe value to utility; but $I$ take it that they do not differ so much from the classical economists in this as they do in the fact that they do not forget what [483] 
values really are and make them relations of quantities rather than quantities themselves, that is, exchange ratios rather than the values upon whose relations exchange ratios are based.

Value is now regarded as quantity of utility-and not quantity of utility merely, but quantity of final, or marginal utility. Marginal utility being a function of human desire, which is variable, and of desire-satisfying commodity, which is also variable, marginal utilities may rise or fall either separately or all together. There is, then, such a thing as a general rise or fall of values, of the values of individual commodities; and there is also such a thing as a general rise or fall in the sum total of values, or in total value, as we shall call it. If we consider all wealth in a lump and society as the valuer of that wealth, total value is equal to commodities, measured by physical standards, multiplied by the marginal utility of commodities. Commodities are the multiplicand, marginal utility the multiplier.

Right here we meet with a most serious difficulty. Careful analysis reveals final utility or final disutility as the true unit of value.* But it is not a tangible unit, its application to the actual measurement of value is impracticable. Things undoubtedly do more or less perfectly exchange for each other in the ratio of their final utilities (to society) and we may confidently believe that society as a whole stops working and capitalizing when the disutility of production comes to equal the utility of consumption. But, until society shall become a far more self-conscious organism than it is now and its final increment of satisfaction or dissatisfaction body itself forth in clear cut definiteness, it will be impossible to measure wealth with scientific accuracy.

\footnotetext{
* See an article on the "Ultimate Standard of Value" in the Yale Review for November, 1892 , by Professor John B. Clark. At the margin of social production and consumption the disutility of production equals the utility of consumption, so that either final utility or final disutility may be taken as the unit of value. Deeming disutility more measurable than utility, Professor Clark adopts the final disutility of the labor and capitalization of society as the ultimate unit of value.
} 
That time may never come.* For the present at any rate economists must content themselves with more or less unsatisfactory indications as to whether values and total value are rising or falling. But more satisfactory conclusions may be reached as to the former than as to the latter. Innumerable inventions and improvements in production have led to such a multiplication of goods that their marginal utilities can hardly have failed to fall. It is argued by some, however, that these dynamic influences in production are more than offset by countervailing dynamic influences in consumption. The diversification of consumption, the genesis of new wants and the formation of complementary consumption groups ministering to the higher nature $\dagger$ all operate to raise marginal utilities. "The increase of industrial efficiency," says Professor Patten, "is used in supplying new wants of greater intensity instead of supplying old wants more completely. At the same time every increase in the variety of consumption enables society to transfer its labors from the margin of production in the old occupations to new occupations. With every change in a dynamic society the marginal increment of consumption supplies a more intense want and hence marginal values of commodities rise."' $\ddagger$ As working with these forces may be mentioned another factor, namely, the fact that the possession of wealth is becoming more general; involving the

* But the words of Jevons are encouraging. Apropos of objections that the notions of Economics are incapable of measurement he says: "If we trace the history of other sciences we gather no lessons of discouragement. In the case of almost everything which is now exactly measured we can go back to the age when the vaguest notions prevailed. Previous to the time of Pascal who would have thought of measuring doubt and belief? $*_{*} * * * *$

"There are sciences which even within the memory of men now living have become exactly quantitative. While Quesnay and Baudeau and I,e Trosne and Condillac were founding Political Economy in France and Adam Smith in Fngland, electricity was a vague phenomenon which was known, indeed, to be capable of becoming greater or less, but was not measured nor calculated : it is within the last forty or fifty years that a mathematical theory of electricity founded on exact data has been established, etc." Pblitical Economy, p. 8.

t See Professor Patten's paper on the "Economic Causes of Moral Progress" in the ANNals for September, 1892.

† Patten's "Theory of Dynamic Economics," p. 69. 
consequence that many wants of poor consumers hitherto unsatisfied are now being satisfied.

But we believe the dynamic influences tending to lower marginal utilities are stronger than those tending to raise them. Such has become the command of man over nature that wants both new and old are, compared with past provision, abundantly met. The range of consumption to-day is far wider than it was a century ago, but the supply of consumption goods, even of those created to meet new wants, is so much larger in proportion to the number of consumers that marginal utilities, it would seem, cannot but have fallen. And this offsetting and more than offsetting is likely to go on in the future as it has in the past, involving a continuous decline in marginal utilities.

But this decline in marginal utilities does not mean that total value is falling. The multiplication of goods is in all probability proceeding so much faster than the decline of their marginal utilities that total value is rising steadily if not rapidly. But a point will ultimately be reached where the rate of multiplication no longer exceeds the rate of decline. Then total value will have attained its high-water mark and will begin to recede. If goods at last become as plentiful as air and water value will vanish entirely.* This phenomenon of decreasing value with increasing goods is Wieser's " paradox of value." $\dagger$ But the total disappearance of value is highly improbable. To all human ken the scarcity of elementary utilities alone would prevent it.

We come now to the relation that exists or ought to exist between money and value. The proper function of money is not only to serve as a medium of exchange and thereby to register ratios between values, $\ddagger$ but also to represent or indicate or reflect, not measure, values and total value. In

* Already some things are so cheap that the state pays for them and distributes them to its citizens gratis. Smart's "Introduction to the Theory of Value," p. 13.

† Wieser's Natürlicher Werth, pp. 18-2x, 27-32. Smart in the appendix of his Introduction gives the substance of Wieser's discussion.

f Using value in its true meaning of quantity of final utility. 
performing this latter function money will also perform the function of a standard of deferred payments.

The "ideal" money of the older writers was conceived in conformity with the idea of value as a relation. The function of money according to this conception is simply to express ratios of exchange. Ideal money need have no intrinsic value whatever. It is, in the language of Sir James Stetuart, simply "a general, determinate and invariable scale," "an ideal scale of equal parts," "an arbitrary scale of equal parts invented for measuring the respective values of things vendible." This conception of money founded on the old idea of value as a relation still colors the thinking of writers on money. Says President Francis A. Walker in his Money, p. 288: "I apprehend that this notion of money serving as a common measure of value is wholly fanciful ;* indeed, the very phrase seems to indicate a misconception. Value is a relation. $\dagger$ Relations may be expressed, but not measured. You cannot measure the relation of a mile to a furlong: you express it as 8 to r." Accordingly, Walker calls money the "denominator of value" in place of the measure of value. Even Jevons, the propounder of the final utility theory of value, in discussing the function of money as a standard of deferred payments begins a sentence thus, "Bearing in mind that value is only the ratio of quantities exchanged." $\ddagger$

Opposed to the conception of an ideal money founded on value as relation stands the true conception of ideal money founded on value as quantity. This latter conception is the only conception of money that accords with the subjective theory of value, a theory which makes of value final utility considered quantitatively. This conception of money is the logical outcome and the necessary complement of the final utility theory of value. If value is quantitative; if individual values can rise and fall, not only relatively, but

- we shall revert to this later.

† The italicising is the present writer's.

I "Money and the Mechanism of Exchange," p. 15.

[487] 
absolutely; if total value can rise and fall: then the prime function of money is to represent value and to reflect accurately its every movement. It would do this, of course, through the medium of price. The prices of things would move in perfect unison with the values of things and the sum of the prices of all things, or total price, would move in perfect unison with the sum of the values of all things, or total value. Price would then be a mirror in which from year to year and from century to century men could watch the fluctuations of value, could mayhap see enacted the paradox of value.

This ideal money may seem highly chimerical* It is so. We can approximate it only very distantly. It is, in fact, just as chimerical as the ultimate unit of value. Indeed, the chimericalness of the one is the chimericalness of the other. And, if it is competent to economists to reason about the one, it is equally competent to them to reason about the other. Sound reasoning is not invalidated because there is no immediate prospect of testing the truth of its conclusions by inductive proof.

Two conditions are essential to the complete achievement of the perfect money system. The first is the materialization, as it were, of the ultimate unit of value and its practical application to the measurement of value. The second is such regulation by government of the amount of money that prices and total price shall correspond exactly with value and total value. The first of these conditions has little hope of early fulfillment. But given its fulfillment and we could confidently predict from the growing wisdom, judgment and firmness with which governments deal with monetary problems that the second condition would ere long be fulfilled too. $\dagger$

The realization of the ultimate unit of value is, as far as we can tell now, a chimera. Nevertheless, as we have

* See note, $p .93$.

†The question whether the money material of the future will be something baving other utility than its utility as money need not be broached here.

[488] 
seen, there are indications that enable us to form more or less probable surmises as to value movements. These indications must serve the legislator, however poorly, as a guide in regulating the amount of money. It will be remembered that we concluded that total value is growing apace-and this notwithstanding marginal utilities are falling; the cause being that goods are increasing more rapidly than their marginal utilities are decreasing. It may be that bi-metallism is necessary in order that prices may not fall faster than values and that total price may keep pace with total value. But, as it is foreign to the purpose of this paper to discuss bi-metallism, there is no occasion to consider the arguments of the mono-metallists; the most germane of which to the question before us is that the use of two metals instead of one simply means a higher level of prices, but a level which can be maintained no better than the lower level which exists when only one metal is used.*

As no attempt whatever is made to secure conformity between price and (final utility) value, $\uparrow$ the fact being that naturally no such attempt could be made before the true conception of value emerged, it is obvious that our statistics of wealth taken from time to time are not an accurate index of value movements. But for periods not too long they are doubtless worth something. The falling prices and growing wealth revealed by statistics accord in direction if not in extent with the movements in value which most probably are going on.

A money composed of the precious metals has two distinct uses from which its value arises-its money use and its commodity use. As money, its service is that of general purchasing power; as commodity, its service is that rendered by plate or jewelry or what not. Its final utility in either capacity is the same ; $\ddagger$ for, if this were not so, enough of it would

* See Giffen's "Case Against Bi-metallism," p. 74.

$\dagger$ We shall see presently that some effort is made to cause prices to correspond with what we shall designate as absolute utility value.

Its final utility as general purchasing power is equal, of course, to the final utility of the things it will buy. 
flow from one use to the other to bring its final utility in the two together. But, its money use being its principal use, the final utility of a money composed of the precious metals is dominated by its final utility as money, by the final utility of its general purchasing power. In the case of a money composed of inconvertible paper, since it can serve no other purpose than that of general purchasing power, its final utility as general purchasing power is its only final utility.

When things exchange against each other in the market it means that their final utilities are the same.* Whence it follows that the final utility of a thing equals the final utility of the money which it brings when sold. From this the conclusion might hastily be drawn that, if we ascertain prices and total price, we ascertain also values and total value. But a moment's reflection will show the error of this. Price under our present unscientific money system is no index of value. Iet us in imagination suppose the point of maximum value in Wieser's paradox of value long since passed and the zero point at the end of the downward road to no-value nearly reached. Commodities exist in almost endless profusion. If the quantity of money is in proportion to the quantity of other things, prices will be as high as ever and total price will be enormous. But values and total value are little short of nothing.

President Walker, as has been already noted, objects to money being called a measure of value. He does this because money need have no intrinsic value whatever and because, if it has, there is likely to be little correspondence between this and its exchange value. "I apprehend," he says, "that this notion of money serving as a common measure of value is wholly fanciful." "If money is to measure value, it must itself possess value, as that which measures length or capacity possesses length or capacity." It is true that, apart from its general purchasing power arising out of

* That is, their final utilities to society. If they were the same to the individual parties to the exchange, the exchange would not take place, as there would be nothing to gain by it. 
its being the medium of exchange, money need have no value. And in fact our perfect money, with its amount regulated by government with scientific precision, would probably be composed of a material possessing little value until it was invested with the money power. But, although President Walker is right and money is not the measure of value, we have seen that it is or ought to be the index or reflector of value.

We have said that the perfect money in serving as the index or reflector of value would at the same time serve as the correct standard of deferred payments. It would do this because a dollar would stand for the same value one year as another. No matter how long a debt ran the repayment of the same number of dollars as was borrowed would be the repayment of the same value as was borrowed. That goods are borrowed only on account of their value, in short that it is value which is the real subject of loan will hardly be denied. In fact, what the borrower generally gets is not goods, but the representative of pure value, that is, money or credit. What particular concrete form it shall take, whether of capital goods or of consumption goods, is wholly irrelevant: the borrower is expected to restore an equal amount of value.

Professor Boehm-Bawerk claims that, because of the difference in value between present and future goods, the interest paid plus the capital sum re-imbursed only together are equal to the amount borrowed. But we assume a perfect equivalence in value between the amount borrowed and the capital sum re-imbursed. Interest we consider no part of the quantum of value which is the subject of loan, though connected, in its origin and amount, with the actual or potential use of that value in production. We shall not concern ourselves with interest except to say that, as the interest on a debt is paid in the same medium as the principal, there exists a two fold reason why the medium should have a stable value.

The justice of the debtor's re-paying to the creditor a value equal to the value received need not be defended, as it 
is seldom seriously assailed.* No advocate of a just standard of deferred payments professes to hold any other ideal of justice. But many do, in effect, seek the return of other than equal value by reason of their false conceptions of value. Some, for instance, demand the re-imbursement, not of the same quantity of goods as was borrowed, but of a quantity of goods embodying the same amount of labor. This is obviously a reversion to the now rejected labor theory of value.

But a far larger number of writers, in fact the majority, hold that the creditor should get back the same quantity of goods that he lent or be paid a sum of money that would buy the same quantity of goods that the money he lent would buy at the time it was lent; which comes to the same thing. Two ways of securing this end might be adoptedthe maintenance of general prices at the same level and the use of the multiple standard. Though the latter is perhaps the more feasible plan in the present state of government control of money, it is only the former that states have attempted at all to introduce. The silver legislation of the United States and the efforts made to obtain international bi-metallism are largely attributable to a desire to secure through the maintenance of a constant level of prices the liquidation of debts by the return of equal quantities of goods.

Now it probably never occurred to the champions of this standard of deferred payments, which may be called the commodity standard, that it involves a theory of value never explicitly enunciated and never implicitly assumed except by themselves. But such would appear to be the case. This theory of value corresponds with neither of the two great value theories, the cost of production theory $\dagger$ and the final utility theory. When a debtor returns the same quantity of goods that he borrowed there is no reason to think that he has returned the same amount of labor and abstinence

* See Prof. Ross' paper, p. 4I.

+ This passage assumes that the labor theory and the cost of production theory whether in its cruder or its more perfect forms may roughly be classed together.

[492] 
or the same amount of final utility. On the contrary, it is pretty certain that he has not done so. Neither the cost of production theory nor the final utility theory of value is involved in the commodity standard of deferred payments. What theory, then, is involved? A theory that may be called the absolute utility theory.

For, barring any changes in consumption, such as the genesis of new wants, the decadence of old wants and the shifting of the emphasis of desire from one good or class of goods to another, the absolute want-satisfying power, the absolute utility of a given quantity of goods composed with reference to the prevailing standard of social consumption, remains the same; but its final utility changes with every change in production and supply. We will say nothing of the abstraction which ignores changes on the side of consumption and consider only that which ignores changes on the side of production. Let us, as the advocates of the commodity standard of deferred payments do by implication, suppose human desire to be an invariable factor in the problem of value : then absolute utility remains constant. But absolute utility is not value. To the conception of value is necessary, not only the idea of absolute utility, but also the limiting idea of quantity of commodity, of largeness or smallness of supply.* Given both ideas and we arrive at the conception of final utility, which considered quantitatively is value. But the upholders of the commodity standard have omitted altogether the limiting idea and made value the same thing as absolute utility. Even Jevons, the herald of the final utility theory, relapses into the absolute utility theory when he advocates the multiple standard. The older economists felt that the utility of a commodity had something to do with its value, but, as they did not perceive the exact significance of the plentifulness or the scarcity of the commodity, the idea of final utility escaped them. But they did not make the blunder of later economic

* Each increment added to tine supply has less utility than the preceding increment. The utility of the last increment is the final utility. 
writers on movey and the standard of deferred payments and confound absoiute utility with value. Not divining the true relation of utility to value, they based value on something else; though still recognizing a dimly apprehended connection between the two.*

We are compelled, then, to reject the commodity standard of deferred payments because it involves a false theory of value. But we have found that the use of the perfect money as the standard of deferred payments would not involve a false theory of value, but the reverse, and that it would guarantee in all loan transactions the restoration of value for value, value being properly conceived. The difficulty lies, of course, in realizing the perfect money. Yet, just so far as price movements correspond to value movements, just so far does the payment of debts by as many dollars as were borrowed approach ideal justice. That is, to the extent that existing money systems approximate the ideal money system, to that extent do they approximate the ideal standard of deferred payments. The perfect money is the perfect standard of deferred payments.

If, as seems likely, the falling prices of the present period correspond to falling values, the discharge of debts by repaying the same number of dollars as was borrowed is just. But it is just only as far as the correspondence is exact. It may be that prices are falling faster than values. If so, injustice is of course being done to debtors.

The final utility of consumption equaling the final disutility of production, value may be measured by either final utility or final disutility. Hence, it may be objected that to insist upon the return of equal value in debt-paying is to revert to something very like the old labor theory of value. To which it may be replied in the first place that the sacrifice of production has been far more carefully analyzed and

"Instance J. S. Mill when he says, "The exchange value of a thing may fall short to any amount of its value in use; but that it can ever exceed the value in use implies a contradiction; it supposes that persons will give to possess a thing more than the utmost value which they put upon it as a means of gratifying their Inclinations." 
correctly conceived $*$ in the new theory of value than in the old labor theory; and in the second place that the new theory does not make value depend on sacrifice, but on final utility. It is only an incident in the new theory and not of its essence that final disutility coincides with final utility. But the third consideration is the most important: which is that with the growing productive efficiency of men the disutility of production is conning to be made up more and more, not of the direct sacrifice of labor, but of the indirect. The direct sacrifice is the weariness and exhaustion of labor itself, the indirect is the negative utility of being kept by the confinement of work from enjoying what is already produced as well as the free goods of nature. Because of this negative utility of non-consumption, which is tantamount in production to disutility, the point at which the disutility of production is equal to the utility of consumption comes earlier in the day. $t$ Society works shorter hours.

These considerations give a new complexion to the fact that the restoration of equal value, or equal amounts of final utility, means also the restoration of equal amounts of final disutility. For we see that, if regard be had only to the actual disutility and not to the negative utility which together make up the final disutility of production, the sacrifice entailed upon the debtor in the payment of a debt with our perfect money as the standard of deferred payments would be less than that undergone by the creditor. He would

\footnotetext{
* It has been discovered that it is the pain of the last increment of labor, $i, c$, the final disutility of labor, with which value has to do; and, morever, not the final disutility of labor to the individual, but to society, ietc.
}

† Prof. Clark counts as part of the disutility of production this negative utility of non-consumption and considers total final disutility, thus made up, equal to final utility. Prof. Patten, on the other hand, regards the margin between direct final disutility and final utility as a isurplus. "When, however, the productive power of society has increased beyond a certain point the efficiency of the workman becomes so great that the time needed to consume what he has produced cuts into the time needed for production, he ceases to work before the pain of the last increment of production equals the utility of the last increnient of consumption. There is for the efficient workmen a surplus at the margin of production equal to the pleasure that could be obtained in using their time in unproductive consumption." -Theory of Dynamic Economics, p. 71. See also p. 57. 
return a less quantity of effective disutility than he had borrowed.

Value is a social, not an individual phenomenon. And value is measured by the final utility of consumption or the final disutility of production, not of the individual, but of society.* The existence of certain ratios of exchange between a given commodity and other commodities simply means that society as a whole obtains as much pleasure from consuming the commodity as it suffers pain from producing enough of other commodities to buy it from its producer at the ruling price. But in this there is no assurance that final utility and final disutility are equal in the case of individual producers. In fact, it becomes clear on observation that the equivalence frequently does not exist. The mere preservation of life is accounted so high and men are psychologically so constructed that the final disutility of production may never exceed the final utility of consumption, even in the case of the inefficient and overworked. But it may often fall short of it. The rich or capable producer who is already well off or whose labor is above the average in productiveness does not need to suffer the discomforts of long hours. Likewise, there exists no relation of equivalence between the final increments of producer's sacrifice and consumer's pleasure in the case of those who have a monopoly either natural or artificial, either whole or partial, and whose products in consequence sell disproportionately high. The same thing is true of all who possess any peculiar advantage in production whatever it is.

The significance of these inequalities of opportunity in relation to the problem of debt-paying becomes apparent when it is remembered that debts are discharged by the requital of value for value and that it is society which values a man's product. The burden is seen to bear particularly heavy on the ill-favored producer. Although it may be claimed-and with some truth-that the ill-favored producer suffers no peculiar hardship as debtor, since the sum borrowed affords

* See Prof. Clark's article in the Yale Review, Nov., 8892.

[496] 
him in his poverty an especially high degree of satisfaction and since he has to make no greater sacrifice in paying the debt than he would have had to make had he in the first place produced the value which instead he borrowed. But society is dynamic and the relative position of a man as producer may change between the dates of debt contraction and debt payment. So that, for instance, an unfavoratoly circumstanced producer deeply in debt might conceivably secure the monopoly of some product and pay off his debts with the greatest ease; and vice versa.

From which we see that in respect to debt-paying as well as in all other respects the existence of monopoly or the absence complete or incomplete of competition works great injustice. This is but an added reason why society should strive to obviate the inequalities of opportunity and secure as perfect competition as possible. The advantages possessed by the capable and intelligent producer, being largely due to superior natural endowment, can be only partially equalized and in the equation, final disutilty equals final utility, efficiency must be counted as final disutility in order that the equation shall be true.* But such inequalities of opportunity as are not owing to inherent differences between men it is incumbent upon society to remove as far as it can. $\dagger$

Let us now examine Professor Ross' paper so far as it treats of the relation of value to the standard of deferred payments. For Professor Ross conceives that the problem of the standard of deferred payments is a problem of value. What is the nature of value and what standard of deferred payments will secure that debts shall be paid by the return of a value equal to that borrowed? "Both parties [mono-metallists and bi-metallists]," he says, "admit that the question involved is a question of justice. And as both agree that economic justice consists in the exchange of equal values it

\footnotetext{
* See Prof. Clark's article in the Yale Review.
}

$\dagger$ In order to obviate inequalities of opportunity society will in all probability have to assume itself the performance of certain functions of a public or quasipublic nature that are now left to individuals or corporations. 
follows that the controversy finally hinges on the nature of value." In what follows we will treat as Professor Ross" the arguments he imputes to the bi-metallists; for, as the reader of his paper will observe, they are one with his own.

The chief criticisms to be brought against Professor Ross' paper are that, while avowing himself a believer in the subjective theory of value, which makes value depend on final utility, he misconceives the theory and in reality holds what we have denominated the absolute utility theory of value: that his misconception of the final utility theory and a lingering recollection of the old idea of value as simply ratios of exchange lead him to deny the possibility of a general decline in marginal utilities: and that, in admitting that under conditions of industrial progress debts should be paid by the return of "a slight excess of commodities" in order that the creditor may suffer no loss of social esteem, he virtually concedes that the relative position of the creditor should be maintained in all respects; which can be done only if the creditor receive back the value he lent. We will now address ourselves to the consideration of these criticisms.

On page 42 Professor Ross opposes "labor-value" to " use-value" in very apt language. "The one," he says, "derives value from production, the other from consumption. 'The one looks to cost, the other to utility." And again, "The product or good standing midway between sacrifice and satisfaction is valuable, not because it embodies. past sacrifices, but because it promises future satisfactions." On the next page he writes, "This has compelled a profounder study resulting in the discovery that value is a particular utility-is, in fact, marginal utility." The inference that would naturally be drawn from these citations is that Professor Ross accepts the final utility theory of value. But from the express language held in certain passages and from many implications it is quite evident that it is the absolute utility theory and not the final utility theory which he holds. "The bi-metallist contends," says Professor Ross-and, as before stated, he fathers the arguments which he attributes to. [498] 
the bi-metallists- " that by reason of falling prices the debtor places the creditor in command of more commodities than the original loan would purchase, whereas justice requires that the quantity of commodities lent and the quantity of commodities restored should be equal." Again, "The bimetallist asserts that equal quantities of goods are of equal value, though separated by a period of time." The standard of deferred payments set up in these passages is almost in so many words what we called the commodity standard and the theory of value upheld is the absolute utility theory.

That Professor Ross confuses the absolute utility theory with the final utility theory will appear from a reading of the second paragraph on page 43 , where he accuses the mono-metallists as creditors of being desirous to enforce the labor theory of value, but as monopolists of being in no wise averse to seeing the "use" theory realized in the prices of their products. No better example could be adduced than monopoly prices to show the inadequacy of the labor theory value, but neither could any better example be adduced to show that it is not absolute utility alone but absolute utility limited by considerations respecting supply that determines value; in short, that value depends on final utility. And yet to all seeming Professor Ross confounds the final utility theory of value so well exemplified in monopoly prices with the absolute utility theory of value which, perhaps without realizing the import of what he is doing, he so strenuously advocates in connection with the standard of deferred payments.

But the greatest violence done to the final utility theory is in the passage where Professor Ross denies the possibility of a general decline in final, or marginal, utilities: "Availing themselves of the new doctrine of value, the mono-metallists might claim that, as with cheapened production the abundance of goods increases, their marginal utilities must fall and hence their value. In order to restore to his creditor equal value the debtor must increase the quantity of goods or command over goods sufficiently to offset the fall in marginal utility. But this is fallacious, inasmuch as marginal 
utilities are simply values and a general decline in marginal utilities is as impossible as a general decline in values." The total quantity of matter existing in one form or another may be invariable, but the quantity of it existing in shapes suitable to the satisfaction of human wants is readily susceptible of variation. As long as this is so and as long as man's wants are inconstant and liable to surfeit, * so long is the possibility either of a partial or of a general fall in values, or marginal utilities, incontestable. This passage shows Professor Ross committing the error of the earlier economists who forgot that values are primarily quantities and only secondarily and in a special sense relations between quantities, i. e., exchange ratios.

Professor Ross' conclusion is that " the debtor is not to return a value measured in labor, nor yet a value measured in commodities, but a value measured in objective utility. And with industrial progress this is secured by a slight excess of commodities." In this conclusion we see a slight departure from the commodity standard of deferred payments. Professor Ross' reason for it is this : With the progress of industry and the growth of riches that portion of a man's goods "devoted to satisfying the needs of his social nature" must somewhat increase, else he will suffer loss of social esteem. That is to say, the "objective utility" $\dagger$ of commodities falls with the lapse of time; although for other purposes than the procuring of social esteem the same quantity of commodities affords a man " as much utility one year as another." Therefore, in the discharge of debts the debtor should return to the creditor "a slight excess of commodities" over the commodities borrowed.

This failure to adhere rigidly to the strict commodity standard of deferred payments is significant. Had the deviation only been greater, the right standard, the standard that

\footnotetext{
* In the sense that the desires for air and water are surfeited. We have already remarked that for goods as a whole this condition is very remote. But it is being perceptibly approached.

t All utility is relative to the mind of the individual or of society. All utility, therefore, is subjective either directly or indirectly.
} 
requires the return of value for value, would have been reached. The fact is this. Wealth, which comprises all things valuable, "consists in the relative-weal-constituting elements in man's material environment."* The permanent control of the same amount of value ensures that economically a man shall at all times be in the same position relatively to other men. This position will be kept, not in respect to social esteem merely, but in all respects. The social consideration attaching to the maintenance of a certain style of living is only a part of 'one's general wellbeing. This general well-being will not be disturbed by one's having been a creditor provided only a just standard of deferred payments is enforced. And this just standard demands the requital of value for value whether or no it be the return of commodity for commodity. If the problem of deferred payments is a problem of value, no other ground is tenable.

Johns Hopkins University.

IUCIUS S. MERRIAM.

"Clark's " Philosophy of Wealth," p. 4. 